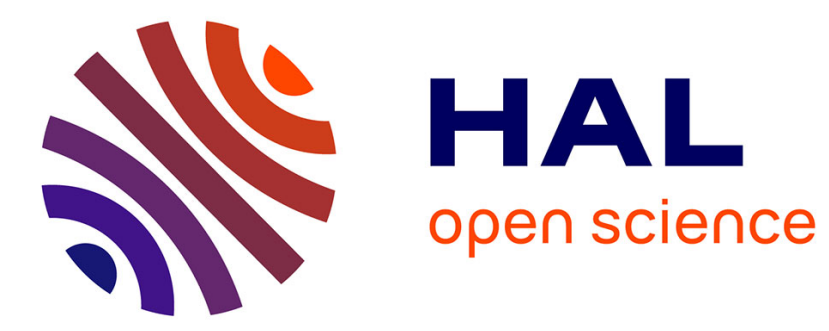

\title{
Group Allegiances and Perceptions of Media Bias
}

\author{
Amarina Ariyanto, Matthew J. Hornsey, Cindy Gallois
}

\section{To cite this version:}

Amarina Ariyanto, Matthew J. Hornsey, Cindy Gallois. Group Allegiances and Perceptions of Media Bias. Group Processes and Intergroup Relations, 2007, 10 (2), pp.266-279. 10.1177/1368430207074733 . hal-00571649

\section{HAL Id: hal-00571649 \\ https://hal.science/hal-00571649}

Submitted on 1 Mar 2011

HAL is a multi-disciplinary open access archive for the deposit and dissemination of scientific research documents, whether they are published or not. The documents may come from teaching and research institutions in France or abroad, or from public or private research centers.
L'archive ouverte pluridisciplinaire HAL, est destinée au dépôt et à la diffusion de documents scientifiques de niveau recherche, publiés ou non, émanant des établissements d'enseignement et de recherche français ou étrangers, des laboratoires publics ou privés. 


\title{
Group Allegiances and Perceptions of Media Bias: Taking Into Account Both the Perceiver and the Source
}

\author{
Amarina Ariyanto \\ University of Indonesia \\ Matthew J. Hornsey and Cindy Gallois \\ University of Queensland
}

People have a tendency to view media reports of intergroup conflicts as biased against their own group (hostile media perception). However, limited research has been conducted investigating how group membership of the perceiver and group membership of the media source combine to influence perceptions of bias. Muslims and Christians in Indonesia $(N=212)$ read an article describing inter-religious conflict. The article was attributed either to a Muslim newspaper, a Christian newspaper, or an unidentified newspaper. Results indicated the hostile media perception only among high identifiers. There was also some evidence for the predicted role of newspaper religion in influencing perceptions of bias: the article was seen to be biased in favor of Muslims when attributed to a Muslim newspaper, biased in favor of Christians when attributed to a Christian newspaper, and intermediate when the newspaper was not identified. The effect of newspaper religion was mediated by prior beliefs of bias. Results are discussed in terms of heuristic explanations of bias perceptions in the media.

KEYWORDS hostile media perception, intergroup relations, social identity

THERE is no doubt that media bias can be real; in all sorts of overt and subtle ways, media can prejudice one argument over another. However, in terms of how people feel about the integrity of media coverage, the extent to which the coverage is objectively biased is less important than people's perceptions of whether it is biased. Furthermore, there is a growing body of evidence that perceptions of bias are influenced by a range of factors that do not relate to the content of the media coverage, but rather are embedded in the intergroup context within which the issue is played out. For example, it has been established that the group membership of the perceiver can have a dramatic effect on the extent to which people perceive media coverage to be balanced or biased (Vallone, Ross, \& Lepper, 1985). One

\footnotetext{
$\overline{\text { Author's note }}$

Address correspondence to Matthew Hornsey, School of Psychology, University of Queensland, St Lucia 4072, Queensland, Australia [email: m.hornsey@psy.uq.edu.au]
} 
might expect that the group allegiances of the media source might also influence perceptions of bias, however currently there is no evidence for this notion. The primary aim of the current study is to examine how the group membership of the perceiver and the group membership of the media source combine to influence perceptions of bias, and to gain insight into the mechanisms by which the group allegiances of perceiver and source influence bias perceptions.

\section{Bias perceptions and the group membership of the perceiver}

When partisans view media reports on an intergroup conflict, members of both sides tend to think the coverage is biased against their group, a phenomenon referred to as 'hostile media perception' (other terms for this phenomenon include 'hostile media bias' and 'hostile media effect'). The fact that both sides tend to view the same media as biased against them suggests that the bias is at least partially one of perception. Furthermore, the bias appears to be fundamentally intergroup in nature. Gunther (1992) found that participants' group membership was the strongest predictor of whether they perceived media to be hostile to their group; in terms of predictive power, it easily outweighed dispositional variables such as age, sex, education, and generalized scepticism toward the media.

A number of theories have been presented with regard to the mechanisms underpinning hostile media perceptions. One theory is that cognitive biases prevent people from 'reading' the media presented to them accurately. For example, when faced with the same information, it could be that partisans selectively attend to and recall items of news that reflect poorly on their own side and selectively ignore or forget items of news that reflect poorly on the opposing side. To date, however, there has been no support for the notion that hostile media perception is caused by selective encoding or retrieval of information (Arpan \& Raney, 2003; Giner-Sorolla \& Chaiken, 1994; Schmitt, Gunther, \& Liebhart, 2004; Vallone et al., 1985). Indeed, recent research suggests that partisans attend to and remember the same content, but categorize a disproportionate amount of this information as favourable to the other side, thus producing hostile media perception (the selective categorization explanation; Schmitt et al., 2004).

An alternative explanation is that people hold a host of biased perceptions regarding their own group's values and behaviors. Thus, when partisans are presented with an objective and balanced view of events, they either feel that the opposing arguments are invalid and not worthy of inclusion, or they feel aggrieved because the media coverage does not converge with their own biased perception of their group's superiority (the 'different standards' explanation). Consistent with this explanation, Giner-Sorolla and Chaiken (1994) found that strength of attitudes toward the Middle East directly predicted perceptions of bias, suggesting that perceptions of media bias are partly influenced by partisans' jaundiced perspective on their group. Schmitt et al. (2004) also found evidence for this notion, but the relationship between perceptions of accuracy and the partisanship of the participants' attitudes was equally strong regardless of whether the story was presented as a news article or as a student essay. This was the case even though perceptions of hostile bias emerged only when the story was presented as a news article; indeed, when presented as a student essay, participants showed some evidence for a reverse effect (biased assimilation). From this pattern of data, the authors concluded that the different standards explanation was not sufficient to explain the perceptions of bias that emerge uniquely when information is presented via the media.

Matheson and Durson (2001) re-examined the different standards explanation using a social identity framework. In line with the social identity perspective (Hogg, 2003; Tajfel \& Turner, 1979; Turner, 1999), they argued that people have a fundamental need to believe that their group is both positive relative to other groups and distinct from other groups. Fair or objective coverage is denigrated as biased because it does not service group members' needs to see their group as positively distinct from the outgroup. 
To examine this, Bosnian Serb and Muslim partisans responded to newspaper reports of a bombing in Sarajevo. Consistent with the social identity perspective, hostile media perception was greater the more people identified with their group, and the link between identification and bias was mediated by perceptions of intergroup distinctiveness. However, the moderating role of identification observed by Matheson and Durson (2001) is somewhat inconsistent with Duck, Terry, and Hogg (1998), who sampled political partisans immediately before and after an election. Unlike Matheson and Durson (2001), Duck and colleagues (1998) found that group identification was not associated with perceptions of bias. Furthermore, Arpan and Raney (2003) found no relationship between perceptions of bias and 'fanship', a construct closely related to identification among their sample of sports followers. It is not immediately clear why the moderating role of identification has emerged in some studies and not in others. However, it is notable that both the studies for which a role of identification was found investigated highlevel intergroup conflict between chronically salient groups (i.e. interethnic and inter-religious warfare), whereas the studies for which no effects of identification were found investigated less extreme intergroup conflicts (i.e. rivalry between political parties and football teams). One possible explanation is that the effects of identification are latent and do not play a major role until activated by very high levels of intergroup threat.

In addition to the cognitive explanation and the different standards explanation of hostile media perception, Giner-Sorolla and Chaiken (1994) suggested that beliefs about media bias developed in the past might play a role in influencing how people view media in the present. Before participants viewed the selection of media presented to them, Giner-Sorolla and Chaiken asked them to rate the extent to which they believed the US mass media in general favored the Israeli or Palestinian side when reporting on the Middle East. They found a weak but significant link between prior beliefs and perceptions of bias in a standardized selection of news reports, independent of other variables such as attitudes toward the Middle East, encoding, and recall. The authors reasoned that prior beliefs about bias in the media generally might operate as a heuristic people use when exposed to specific media reports. If people believe that the media is generally biased against their side, then they need not closely scrutinize the footage they are exposed to for bias; they simply assume it must be there (see also D'Alessio, 2003, who found that participants who were primed to think of media as generally biased reported specific articles to be more biased). Contrary to this explanation, however, Matheson and Dursun (2001) found no relationship between generalized beliefs about media bias and the extent to which participants reported bias when exposed to newspaper articles. It is possible that the discrepancy in results with regard to the influence of prior beliefs reflects the different news stories used by these researchers. The Middle East conflict used by Giner-Sorolla and Chaiken (1994) arguably lends itself to supporting the prior beliefs argument, because the US media is frequently accused of showing allegiance toward Israel and the Jewish community in general. In contrast, Matheson and Durson (2001) used Canadian coverage of the bombing in Sarajevo as their stimulus material, media coverage of which is not stereotypically associated with bias. In short, people arguably have salient and readily formed opinions about whether the US media is capable of reporting the Middle East conflict in a neutral way, whereas there are fewer stereotypes and assumptions to bring to bear on the question of whether the Canadian media is capable of reporting the war in Sarajevo in a balanced way. This might help explain why prior beliefs were predictive in the former case but not the latter.

\section{Taking into account group membership of media}

The research described above makes the important point that people's group memberships affect how they perceive media. However, one point that has not been addressed in this research is that media outlets are often aligned to groups themselves. When people watch a 
CNN report on the Middle East, many of them would be aware that $\mathrm{CNN}$ is a flagship American network, and they would also be aware that the US has traditionally been an ally of Israel. For many Muslims, then, CNN is seen to be a vehicle for US propaganda, and it is reasonable to assume that people might factor this in when deciding whether footage is pro- or anti-Israel. Alternatively, many people in the West view the Muslim broadcasting service $\mathrm{Al}$ Jazeera to be a mouthpiece for pro-Arab, anti-American propaganda. Again, it is reasonable to expect that the group allegiances of this network will be taken into account when people are screening for bias.

This expectation is reinforced by Giner-Sorolla and Chaiken's (1994) observation that beliefs about media bias developed in the past might act as a heuristic that shapes how people view media reports in the present. If people are aware that a media outlet has group allegiances, this might prime them to assume that their reports will be slanted in favor of one group over another. Such an explanation would be consistent with research and theory showing that people are psychologically primed to trust ingroup members and to distrust outgroup members (e.g. Brewer, 1981; Worchel, 1979). For example, it has been found that people generally expect that outgroup members will discriminate against them if they have the chance (Insko, Schopler, Hoyle, Dardis, \& Graetz, 1990; Vivian \& Berkowitz, 1992), and research on group-directed criticism shows that people trust the motives of outgroup members' statements less than those of ingroup members (Hornsey \& Imani, 2004). Indeed, some researchers (e.g. Brewer, 1981; Yamagishi \& Kiyonari, 2000) have argued that group membership operates as a heuristic that helps us gauge who to trust and who not to trust, independent of one's history of interpersonal exchanges. In relation to the current research, such a heuristic might lead people to believe their own group's media could be trusted, but the outgroup media does not have one's group's interests at heart. In turn, this expectation might taint how they view material stemming from that outlet, even if that material is objectively balanced and unbiased.
Although this prediction seems intuitive, there is very little research that has subjected it to empirical scrutiny. An early attempt to take media partisanship into account when explaining perceptions of bias was made by Gunther (1992), who derived a measure of 'political distance'. This was a three-level categorical variable that took into account the political allegiance of the participant (Republican or Democrat) and the political allegiance of the newspapers they chose to read (Republican, Democrat, or Independent). Participants were categorized as being 'close' if the political allegiances of the reader and the newspaper converged (e.g. Democrat reading Democrat newspapers), moderately distant if a politically aligned participant read an Independent newspaper, and very distant if the political allegiances of the reader and the newspaper were in contradiction (e.g. Democrat reading Republican newspapers). Gunther found that political distance had no effect on the extent to which the newspapers were seen to be biased against their group.

An attempt to experimentally examine the role of the group allegiances of the media source was provided by Arpan and Raney (2003). Arpan and Raney examined responses to a fictitious committee report citing off-field problems at two university football teams, one of which represented the university in which the participants were enrolled. The report was reproduced in such a way that participants were led to believe it was published in either the participants' hometown newspaper or in the rival team's hometown newspaper. As expected, participants believed the hometown newspaper and its employees were generally inclined to favor the hometown team more than the rival-town newspaper (Arpan and Raney called this measure 'comparative bias', although the ratings did not relate to the article itself). However, when rating perceptions of bias in the particular news report they were given, no differences emerged regardless of whether the article was published in the hometown newspaper or the rival town's newspaper.

In conjunction with the work by Gunther (1992), this study suggests that the group allegiances of the media source might not be a significant factor in influencing perceptions of 
bias. However, there are a number of methodological problems that may help account for this. The main problem in Gunther's study is that fewer than $10 \%$ of participants read a paper that formally declared its political allegiances, meaning that the overwhelming majority of papers were categorized as 'independent'. Second, only a very small percentage of respondents $(2 \%)$ could be classified as being 'very distant', presumably because people do not typically read newspapers that officially oppose their preferred political party. It is less clear why the effects of media group membership were not found by Arpan and Raney (2003), but one possibility is that the standardized article reported an investigation into scandalous incidents occurring within the preferred teams of both the hometown newspaper and the rival town's newspaper. It is possible, then, that fans of the two teams were momentarily united by a 'them-against-us' mentality, thus activating a shared superordinate identity which diluted the expected intergroup biases. Consistent with this explanation, although the article was perceived to be equally biased when attributed to the home town and the rival town's newspaper, the greatest amount of perceived bias (against both teams) was reported when the article was attributed to a neutral town's newspaper.

\section{The current study}

In the study reported below, we examine how the group allegiances of a newspaper influence the extent to which readers perceive the paper to be biased. In contrast to Gunther (1992), we did so using an experimental design such that the same article was attributed to either an ingroup or an outgroup newspaper. Furthermore, in contrast to Arpan and Raney (2003), we examined this question in relation to a vivid, highlevel intergroup conflict, namely the ongoing conflict between Christians and Muslims in Ambon, Indonesia. We hoped that this more vivid intergroup context would foster an intensity of feeling that would be more conducive to the study of intergroup biases in media perception.

Another motivation for conducting the current studies is that, although hostile media perception is widely regarded to be robust, the generalizability of the effect has yet to be seriously tested. One striking aspect of the research to date is that it has been conducted entirely in Western cultures; specifically the US (D'Alessio, 2003; Giner-Sorolla \& Chaiken, 1994; Gunther, 1992; Gunther, Christen, Liebhart, \& Chia, 2001; Perloff, 1989; Vallone et al., 1985), Canada (Matheson \& Durson, 2001), and Australia (Duck et al., 1998). According to Hofstede (2001), all these cultures are predominately individualist in orientation, with the US qualifying as the most (and Australia as the second most) individualist society of 53 sampled. Individualism is associated with individual freedom and a general emphasis on self-interest and competition among individuals. Conversely, in collectivist cultures people are taught to rely on the group to survive and succeed. Rather than privileging individual endeavor, collectivist cultures are more likely to require respect to group authority and to allow the group to shape people's thoughts, feelings, and behaviors (Hofstede, 1997; Triandis, 1989, 1995; Triandis, Bontempo, Villareal, Asai \& Lucca, 1988). Whereas in individualist cultures people are taught that independence and a critical mind are valuable (even heroic) assets, such qualities are more likely to be seen as immature and dysfunctional in collectivist cultures, where people are taught to respect the hierarchies and rules that govern their social worlds (see, for example, Kim \& Markus, 1999).

Extrapolating from these cross-cultural observations, one might question whether hostile media perception would be as strong in collectivist cultures as in individualist cultures. It could be argued that the hostile media effect has an individualistic flavor to it, in that it involves taking a sceptical and critical stance toward a societal institution (the media). This speculation is difficult to verify, as very little research has been conducted comparing levels of institutional trust across cultures. Furthermore, an alternative argument can be put forward to argue that hostile media perception might be stronger in collectivist cultures, where media reports are more likely to be interpreted through an intergroup lens. One practical reason for this is that in South East Asia, at least, one is more likely to 
see media outlets openly acknowledging their group allegiances than in North America and Australia, where group allegiances of media are more likely to be hidden or covert. A more psychological reason is that there is some evidence that members of collectivist cultures are more predisposed than members of individualist cultures to draw sharp distinctions between ingroup and outgroup members (Triandis, 1972). So although there is a universal tendency for people to cooperate more with members of their own group and to trust members of their ingroup more than members of the outgroup, these tendencies are assumed to be particularly pronounced in collectivist cultures. On the basis of this, then, one might speculate that members of collectivist cultures might be relatively unwilling to criticize their newspaper of their own group, but relatively willing to criticize the integrity of the outgroup's media.

In sum, a reading of the cross-cultural literature does not lead to a clear conclusion as to whether perceptions of hostile media would be more pronounced, less pronounced, or the same in collectivist relative to individualist cultures. Nonetheless, if the hostile media effect is to make a claim to be reflecting fundamental, universal psychological processes, at the very least it would seem important to attempt to replicate the effect in a collectivist culture. The urgency to do so is reinforced by the fact that many biases that have been demonstrated repeatedly in the West have failed to be replicated among Japanese participants (see Heine, Lehman, Markus, \& Kitayama, 1999, for a review). The current studies respond to this gap in the literature by testing hostile media perception within a collectivist culture (according to Hofstede, 2001, Indonesia is the sixth most collectivist culture of 53 cultures sampled).

Another striking facet of previous experiments on hostile media perception is that the perceivers have been geographically removed from the location of the intergroup conflict. Indeed, in many cases, the groups were defined attitudinally rather than on national or religious grounds. For example, Perloff (1989), Vallone et al. (1985), and Giner-Sorolla and Chaiken (1994) obtained some or all of their partisans by measuring attitudes toward the Middle East among students in the US, and splitting them according to whether they were 'pro-Arab', 'pro-Israeli', or 'neutral'. Thus, many of the participants were not of Middle Eastern origin. In addition, all of them were located in the US and were exposed to American news footage. Matheson and Durson (2001) are the only researchers to have used ethnic or religious groups rather than categorizing people along attitudinal lines. However, their sample of Muslims and Serbs were expatriates living in Canada; again, they were geographically removed from the conflict and were exposed to media reports stemming from the West. To respond to these question marks regarding generalizability, the current study examined hostile media perception in a collectivist, non-Western culture (Indonesia) among participants who geographically reside in the area of conflict.

\section{Design and predictions}

Muslim and Christian participants in Indonesia read a newspaper article describing conflict between Muslims and Christians in Ambon. Ambon is an island in Indonesia that, from 2000-2002, was the scene of bloody riots and battles between Muslim and Christian villagers. Over this period, approximately 2000 people lost their lives as a result of these conflicts.

The group allegiance of the newspaper was manipulated by attributing the article either to a Christian newspaper, a Muslim newspaper, or an unidentified newspaper. In line with previous research, we anticipated hostile media perception, such that both Muslims and Christians would view the article to be biased against their own religious group. Furthermore, in line with the social identity interpretation of the different standards explanation (Matheson \& Durson, 2001), we expected that hostile media perceptions would be stronger for high identifiers than for low identifiers. Finally, in light of research emphasizing the heuristic nature of bias perceptions (Giner-Sorolla \& Chaiken, 1994), it was tentatively predicted that participants would perceive greater bias against their religious group when the report was published in an outgroup 
newspaper than when it was published in an ingroup newspaper (perceptions of bias in the unidentified newspaper were expected to lie somewhere in between). This effect was expected to be mediated by prior beliefs of bias, such that people perceive greater bias against their group when the article is attributed to an outgroup newspaper because they have prior beliefs that the outgroup newspaper is biased against their group.

\section{Method}

\section{Participants and design}

Altogether, 262 students from universities in Jakarta participated in the study. Twenty-four of the participants identified themselves as being neither Muslim nor Christian, and so were excluded from analysis. The remaining sample consisted of more female $(N=174)$ than male $(N=64)$ participants, with ages ranging between 16 and 26 ( $M=20.58$ years). The sample comprised 131 Muslims and 107 Christians. Participants received a ballpoint pen as compensation for their time. Participants were randomly allocated to levels of newspaper religion, and levels of identification were formed on the basis of median splits, resulting in a 2 (Participant Religion: Muslim or Christian) $\times 2$ (Identification: high or low) $\times 3$ (Newspaper Religion: Muslim or Christian or unknown newspaper) between groups-design. After the experiment was completed, participants were fully debriefed.

Following the presentation of the newspaper article we asked: 'In what newspaper was the incident reported?' Eighteen participants gave the wrong answer to this question, and another five participants said that they did not know the name of the newspaper. ${ }^{1}$ Finally, three participants did not respond to any of the measures of perceived bias. These participants were all excluded from analysis, leaving a final sample of 212 participants.

\section{Procedure and materials}

After recording their demographic details, participants completed seven items designed to assess identification with their religion. The items were adapted from a scale by Ellemers, Kortekaas, and Ouwerkerk (1999), and included items such as 'This religious group is an important reflection of who I am', 'I would tell many people that I belong to this religious group', and 'I think my religious group has many things to be proud of' ( $1=$ not at all, $7=$ very much; $\alpha=.95)$. Participants were then told that they would be given a newspaper article about the Muslim-Christian conflict in Indonesia. Participants were either told that the article was in Republika (a Muslim newspaper), in Suara Pembaruan (a Christian newspaper), or they were not told the name of the newspaper (unknown condition). Where the name of the newspaper was identified, we made it clear to what religion the newspaper was aligned. After naming the Muslim newspaper, for example, the following appeared: 'Republika newspaper is owned by Muslims. Republika's main target of readers is Muslim people'. Before reading the article, participants were asked to record the last time they had read the newspaper ('today', 'more than 1 week ago', 'more than 1 month ago', 'more than 1 year ago', or 'never'). They also rated the extent to which they believed that the newspaper is generally biased or fair in the reporting of news. For example, in the Christian newspaper condition they were asked: 'When reporting the news, to what extent do you think that Suara Pembaruan favors Christians compared to Muslims?' ( 1 = biased in favor of Christians, 5 = fair and impartial, $9=$ biased in favor of Muslims). This was interpreted as a measure of prior beliefs of bias. Because participants in the unknown condition did not know to which newspaper they were going to be exposed, we did not collect measures of prior beliefs among these participants.

Participants then read a newspaper report describing a conflict between Muslims and Christians. The article-approximately 350 words in length-was adapted from a real newspaper article, describing tit-for-tat raids made by Muslims and Christians, leading to 51 deaths. Adaptations were made to remove references to specific people and places. No commentary or editorializing appeared in the article; rather, the article read as a series of factual observations. 
Above the article was either a masthead from the Christian newspaper Suara Pembaruan, a masthead from the Muslim newspaper Republika, or no masthead (unidentified newspaper condition). ${ }^{2}$

Participants then responded to four items designed to measure the extent to which they perceived the article to be biased. Participants used 9-point scales to rate the extent to which their 'overall impression of the article' was that it was 'biased in favor of Christians' (1) or 'biased in favor of Muslims' (9), the extent to which the article presented a 'stronger case against Muslims' (1) or a 'stronger case against Christians' (9), the extent to which they felt the editor's personal view of the article seemed 'anti-Muslim' (1) or 'anti-Christian' (9), and the extent to which they felt there was 'too much focus on Muslims' bad behavior' (1) or 'too much focus on Christians' bad behavior' (9). In all cases, the midpoint (5) was anchored with the words 'fair and impartial'. All of the items were recoded such that a score of zero represented fairness, positive scores indicated that participants believed the article was biased against Christians, and negative scores indicated that participants believed the article was biased against Muslims. The four items intercorrelated strongly and so were combined into a single measure of perceived bias $(\alpha=.90)$.

\section{Results}

An initial 2 (Participant Religion) $\times 3$ (Newspaper Religion) analysis of variance (ANOVA) on the identification scores revealed no significant main or interaction effects (all $F \mathrm{~s}<1$ ). Thus, perceptions of bias were analyzed using a 2 (Participant Religion: Muslim or Christian) $\times 2$ (Identification: high or low) $\times 3$ (Newspaper Religion: Muslim or Christian or unknown) between groups ANOVA. ${ }^{3}$ In order to rule out the possibility that we were confounding identification and religion, we performed separate median splits for Muslims (low identifiers, $M=3.47$; high identifiers, $M=6.29$ ) and for Christian participants (low identifiers, $M=3.76$; high identifiers, $M=6.36) .{ }^{4}$ Preliminary analyses showed that the effects remained the same regardless of whether or not we covaried out age and sex, so the analyses were reported without covariates included.

Analyses on ratings of perceived bias revealed a significant main effect of religion, $\left(F(1,200)=16.17, p<.001, \eta^{2}=.08\right)$. Muslim participants tended to rate the article as biased against Muslims $(M=-0.12, S D=0.86)$ and Christian participants evaluated it as biased against Christians $(M=0.40, S D=1.17)$. Single sample $t$ tests were then conducted to examine whether the levels of bias exhibited by each group was significantly different from zero. The result showed that the level of bias was significant for Christians $(t(90)=3.28$, $p<.001)$, but not significant for Muslims $(t(120)=$ $-1.51, p=.13)$.

The main effect of religion, however, was qualified by a significant interaction between religion and identification $(F(1,200)=8.43, p=.004$, $\left.\eta^{2}=.04\right)$. Analysis of simple main effects revealed a significant effect of participant religion for high identifiers in line with the hostile media effect $(F(1,200)=23.48, p<.001)$. As can be seen in Table 1, strongly identified Christians perceived the article as favoring Muslims, whereas strongly identified Muslims rated the article as favoring Christians. Single sample $t$ tests showed that the level of bias was significantly different from zero for both Muslims $(t(60)=2.75, p=.008)$, and Christians $(t(42)=3.34, p=.002)$. In contrast, for low identifiers, Muslims and Christians did not differ in their perceptions of bias $(F(1,200)=$ $0.64, p=.43)$.

Consistent with predictions, a significant main effect of newspaper also emerged on perceptions of bias $(F(2,200)=8.61, p<.001$, $\left.\eta^{2}=.08\right)$. Collapsing across religious background, participants who read the article in a Muslim newspaper evaluated the article as biased against Christians $(M=0.47, S D=1.02)$, whereas those who read the article in a Christian newspaper rated the article as biased against Muslims $(M=-0.25, S D=1.04)$. Collapsing across religious background, participants who read the article in an unidentified newspaper evaluated the article as relatively fair $(M=0.07$, $S D=0.94)$. Duncan's pos thoc tests showed that all the conditions differed significantly from 
Table 1. Effects of identification and participant religion on perceived bias

\begin{tabular}{lcc}
\hline & High identifiers & Low identifiers \\
\hline Muslims & $-0.30^{* *}(0.89)$ & $0.03(0.79)$ \\
& $n=61$ & $n=60$ \\
Christians & $0.63^{* *}(1.22)$ & $0.18(1.10)$ \\
& $n=43$ & $n=48$ \\
\hline
\end{tabular}

Notes: Positive scores indicate a perception of bias against Christians and negative scores indicate a perception of bias against Muslims. Asterisks indicate that the score is significantly different from zero using single-sample $t$ test: $* * p<.01$. Numbers in parentheses are standard deviations.

each other in terms of the amount of bias. Single sample $t$ tests showed that the level of bias was significantly different from zero for the Muslim newspaper $(t(69)=3.84, p<.001)$, marginally significant for the Christian newspaper $(t(63)$ $=-1.92, p=.06)$, and was not significant in the unidentified condition $(t(77)=.69, p=.49)$.

It should be noted that no main effect of identification emerged $(F(1,200)=0.18, p=.68)$, and the interaction between identification and newspaper was likewise nonsignificant $(F(2,200)=$ $0.66, p=.52)$. Finally, the interaction between newspaper and religion $(F(1,200)=0.18, p=.68)$ and the three-way interaction $(F(2,200)=0.25$, $p=.78)$ were nonsignificant.

\section{The role of prior beliefs}

As we argued earlier, one possible reason for these results is that people have prior beliefs that group-aligned media favor their own group, and these beliefs tainted the way they interpreted the article. Because participants in the unidentified condition did not rate their prior beliefs, the mediating role of prior beliefs was examined only for participants in the Christian newspaper and the Muslim newspaper conditions. Consistent with predictions, a 2 (Participant Religion: Muslim or Christian $) \times 2$ (Identification: high or low $) \times 2$ (Newspaper Religion: Muslim or Christian) between groups ANOVA on prior beliefs revealed a significant main effect of newspaper religion $\left(F(1,122)=54.42, p<.001, \eta^{2}=.31\right)$. Whereas people believed that the Christian newspaper would be biased in favor of Christians $(M=-0.42$,
$S D=1.14)$, they also believed that the Muslim newspaper would be biased in favor of Muslims $(M=1.30, S D=1.41)$.

There was also a weaker interaction between participant religion and newspaper religion $\left(F(1,122)=5.93, p=.016, \eta^{2}=.05\right)$. Muslims believed the Christian newspaper to be more biased against Muslims $(M=-0.83, S D=1.28)$ than did Christians $(M=0.11, S D=0.63)$, $(F(1,122)=8.37, p=.005)$. In contrast, Muslims $(M=1.38, S D=1.31)$ and Christians $(M=1.19$, $S D=1.57$ ) believed the Muslim newspaper to be equally biased against Christians $(F(1,122)=0.29$, $p=.60)$. It should be noted, though, that both Muslims $(F(1,122)=56.26, p=.000)$ and Christians $(F(1,122)=10.67, p=.001)$ felt that the Muslim newspaper favored Muslims more than did the Christian newspaper. No main effects of religion $(F(1,122)=2.85, p=.094)$, or identification emerged $(F(1,122)=0.32, p=.57)$, and these variables did not interact $(F(1,122)=$ $1.10, p=.30)$. Identification did not interact with newspaper $(F(1,122)=0.00, p=.96)$, and the three-way interaction was likewise nonsignificant $(F(1,122)=1.75, p=.19)$.

Because the effects of newspaper religion on prior beliefs mirrored the effects of newspaper religion on perceived bias, we were encouraged to explore further the mediating role of prior beliefs. As can be seen in Figure 1, when newspaper religion (dummy coded such that $0=$ Muslim newspaper and $1=$ Christian newspaper) and the other independent variables were entered in a regression model, newspaper religion significantly predicted perceptions of bias. But when prior beliefs was entered into the model, the predictive value of newspaper religion dropped to nonsignificance. This reduction in explained variance was significant according to the Sobel test $(z=-4.51, p<.001)$, showing that the effect of newspaper religion on perceptions of bias was fully mediated by prior beliefs about the extent to which the newspaper was biased. We also tested the reverse model, in other words we tested to see if perceptions of bias mediated the relationship between newspaper religion and prior beliefs about bias. When perceptions of bias were entered in the regression along with the independent variables, the relationship 


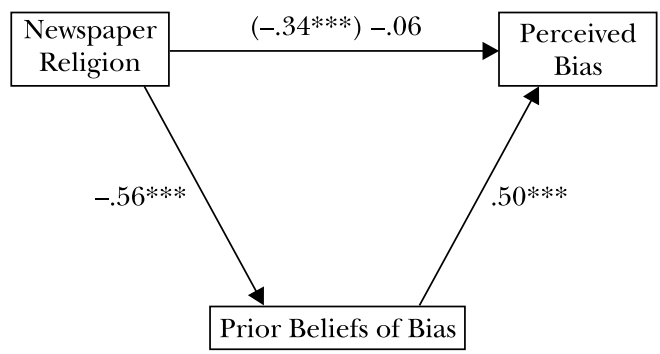

Figure 1. The role of prior beliefs in mediating the effects of newspaper religion on perceived bias.

Note: The coefficient in parentheses represents the direct effect with no mediator in the model. The coefficient to the right represents the direct effect when the mediator (prior beliefs) is included in the model.

between newspaper religion and prior beliefs remained highly significant $(\beta=-.42, p<.001)$, reinforcing our confidence in the integrity of the original causal model.

At this point it is not clear where these prior beliefs stem from in the first place. One possibility is that people have beliefs that media would favor their constituency, and that these beliefs emerge independent of experience with that media outlet. An alternative possibility is that Suara Pembaruan and Republika are, in fact, biased in their news reporting, and that our participants are simply recognizing this. If the latter explanation is true, it suggests caution needs to be applied before generalizing beyond the current data.

Fortunately, we are in a position to make a judgment about this. Before exposing participants to the article we asked them the extent to which they had experience with Suara Pembaruan or Republika (depending on condition). Of those who were asked this question, a small subsample $(n=29)$ indicated they had never read these newspapers. All the same, analysis of variance showed that these participants-who had never read the newspaper-still expected that Republika would favor Muslims $(M=1.15, S D=1.42)$ significantly more than would Suara Pembaruan $(M=-0.33, S D=0.71)(F(1,27)=8.67, p=.008$, $\left.\eta^{2}=.24\right)$. This suggests that expectations of bias are influenced by heuristics associated with knowledge of group allegiance per se rather than (or as well as) by experience with the specific outlets used in this study.

\section{Discussion}

Consistent with research on hostile media perception, Muslims and Christians differed quite markedly in terms of how they perceived the same standardized newspaper article. Whereas Christians believed the article was biased against Christians, there was a (nonsignificant) trend for Muslims to see the article as being biased against Muslims. The fact that we found some support for the hostile media effect in (a) a collectivist culture, and (b) using participants who were geographically located within the country of conflict, reinforces the proposition that hostile media perception has cross-cultural generalizability.

It is interesting to note that Christians in the current sample showed a significant tendency to perceive the media as biased against Christians, whereas the tendency for Muslims to perceive the media as biased against Muslims registered only as a nonsignificant trend. One possible explanation for this relates to the sociohistorical context of the areas in which the study was conducted. In Indonesia, Christians are a minority in terms of population and political power, and have traditionally suffered from persecution as a result. It is possible, then, that this group would have had a particularly strong motivation to defend the integrity of the group and might have had particularly negative expectations about the capacity of the media to present information fairly. Although this conclusion is speculative, it might be that minority groups are more inclined to see the media as biased than are majority groups.

One explanation for hostile media perception is that people hold a distorted perception of the value and integrity of their group. For this reason, neutral or balanced reporting is seen to be biased against their group because it does not reflect the partisan's own distorted world view. The moderating role of identification observed in the current study lends support to this explanation. Whereas high identifiers from both religions showed a sizable hostile media 
effect, low identifiers did not show the bias at all. One explanation for this is that high identifiers are more likely than low identifiers to hold distorted or inflated views about their group's worth, and so will be more critical of the article when it does not reflect this perception.

The role of identification in moderating the hostile media effect is consistent with Matheson and Durson (2001), but inconsistent with two other studies which found no evidence that identification was implicated in hostile media perception (Arpan \& Raney, 2003; Duck et al., 1998). As noted earlier, the studies for which a role of identification has been found investigated high-level intergroup conflict between chronically salient groups, whereas the studies for which no effects of identification were found investigated more benign intergroup contexts. Whether the moderating role of identification is generalizable beyond examples of extreme intergroup conflict is a question for future research. However, it should be noted that where hostile media perception effect has not emerged-for example Vallone et al.'s (1985) analysis of the 1980 US election and GinerSorolla \& Chaiken's (1994) null findings with respect to the abortion issue-the authors have informally accounted for this by highlighting the relatively low levels of partisanship in their sample. The current findings-showing hostile media perception for high but not for low identifiers-might provide a formal framework through which these conflicting results can be explained.

Furthermore, it should be noted that although the moderating role of identification seems consistent with a different standards explanation of hostile media perception, in itself it does not provide definitive evidence that perceptions of different standards are the psychological mechanism through which hostile media perceptions emerge. A stringent test of the different standards explanation would require (a) more concrete and specific measures of one's regard for the ingroup, and (b) some evidence that these perceptions underpin perceptions of media bias over and above perceptions of bias per se (see Schmitt et al., 2004, for an elaboration of the latter point). In short, although the current data do suggest that identification (or partisanship) is critical in predicting perceptions of hostile media, the evidence that this provides for the different standards explanation remains somewhat circumstantial.

\section{The role of newspaper religion}

The primary aim of this research was to examine how the group allegiance of the media affects perceptions of bias. We argued that, when screening the media for bias, people take into account the group allegiances of the media. For example, if Muslims were reading an article on inter-religious conflict in a Christian newspaper, it seems reasonable to assume that they would anticipate more bias against their group than if they read an article in a Muslim newspaper. Muslim perceivers might then view the article through this lens, such that even neutral material is seen to be hostile to their group. Consistent with predictions, participants believed that the article was biased toward Christians when it was attributed to a Christian newspaper, but when the same article was attributed to a Muslim newspaper, the participants believed it to be biased toward Muslims. When the newspaper was not revealed, ratings of overall bias were intermediate. The fact that perceptions of bias are influenced not just by the group membership of the perceiver but also by the group allegiances of the media suggests an important boundary condition to the notion that people see media as biased against their own group. Although people might be generally inclined to perceive that media is biased against their group, if the media source is presumed to have ingroup allegiances this perception can be eliminated.

Importantly, we were not only able to find an effect of group media allegiance, but we were also able to articulate why group allegiances of the media might influence perceptions of bias. Specifically, people have prior beliefs that outgroup media outlets are biased against them, and interpret articles from outgroup newspapers in line with these beliefs. Furthermore, this expectation seems to be applied heuristically and independent of experience; even those people who had never read Suara Pembaruan or Republika made assumptions about bias once they 
knew what their religious constituency was. This is consistent with Giner-Sorolla and Chaiken's (1994) proposition that perceptions of bias are partly influenced by prior beliefs about bias in the media. It is also consistent with previous theory and research suggesting that people use group membership as a heuristic about who can be trusted and who cannot (Brewer, 1981; Worchel, 1979; Yamagishi \& Kiyonari, 2000). In the context of the current study, people seem to make assumptions that outgroup media cannot be trusted to report the news fairly. Ironically, their own prejudices about the integrity of the news outlet leads them to confirm their negative expectations.

The current data show that, when predicting perceptions of media bias, we need to be mindful not just of the group membership of the perceiver (as has been the case with traditional work on hostile media perception), but also the group allegiances of the media. Consumers of media do not simply reflect on the content of the message, they peer beyond the words and make assumptions based on whether the media outlet has previous or apparent allegiances of the ingroup or the outgroup (see Hornsey \& Imani, 2004; Hornsey, Trembath, \& Gunthorpe, 2004 , for similar arguments in relation to groupdirected criticism). Where a media outlet has real or imagined group allegiances, their ability to convince outgroup members that they report current affairs in a balanced and fair way may be compromised, even when the reporting is objectively neutral. Although the current data lend some support to the notion that prior beliefs about bias play a role in driving perceptions of bias, the specific cognitive mechanisms by which this occurs has not been articulated clearly. One possibility is that when people have strong expectations of bias they do not elaborate on the content, and instead process it heuristically. The fact that the content was processed through peripheral channels might mean that the underlying neutrality of the content was simply not detected. Another possibility is that the expectations of bias led to biases in how the content was interpreted, remembered, and/or categorized. A priority for future research might be to reconcile the heuristic explanation with more specific cognitive explanations.

Two other limitations of the current study should be noted. To ensure that all participants were aware of the group allegiances of the newspapers, we chose to make the group allegiances of the respective newspapers explicit to participants in the instructions (e.g., by saying Republika was owned by Muslims and targeted by Muslims). One possible consequence of this procedure is that we may have inadvertently cued expectations of bias among the participants, thus artificially strengthening the effects (see D'Alessio, 2003, for a discussion of cuing in relation to perceptions of bias). To avoid this in future studies, it might be beneficial to measure religious identification and prior beliefs about media bias in a pretest a few weeks before the experiment. Finally, in the interests of generalizability, it might be useful to see if the effects of newspaper allegiance can be found in the US and Australia, where mainstream mass media subscribe to an ethic of impartiality and try to hide or diminish their historical allegiances. In many parts of Europe and Asia, group allegiances are declared more openly, potentially exaggerating the effects of newspaper group membership.

In sum, the current study gives a reasonably pessimistic picture about how people read media. Even though the article was scripted to be as balanced and objective as possible, strongly identified (but not weakly identified) Muslims and Christians interpreted it to be biased against their own group. People were particularly likely to label the article as biased against their group if it was attributed to an outgroup media outlet, and this effect was driven by prior beliefs that outgroup media outlets are more biased against the group than are ingroup media outlets. These results suggest it might be difficult to break the cycle of suspicion regarding outgroup news outlets; people heuristically expect that the news will be biased and interpret it in line with this expectation, thus reinforcing the original expectation, and so the cycle continues. Thus, in the short term at least, it appears unlikely that news outlets can deflate accusations of bias 
simply by reporting the news in an objective way, because by virtue of their group membership they are condemned to be judged as biased. In turn, this perception might fuel already tense relations between conflicting groups. Now that the basic phenomenon has been established, the imperative is to find ways of minimizing its destructive effects in areas of extreme intergroup conflict. Attempts to do so will be difficult: Trust is easily lost but, as the current data suggest, difficult to regain.

\section{Notes}

1. When it became clear that a significant number of participants were getting this rather straightforward manipulation check wrong, we began asking people how they felt about this question. A number of people reported that, because the answer seemed so obvious, they thought the experimenters had provided a false masthead and were now asking participants to guess what newspaper the article was really from. This partly reflects the fact that our Indonesian sample is less experienced in doing quantitative surveys than the average Western sample.

2. For those participants who were allocated to the unidentified condition, we asked them the extent to which they thought the article was published in a Christian or a Muslim newspaper ( 1 = definitely Muslim newspaper, 5 = unsure, $9=$ definitely Christian newspaper). Christians were marginally more willing to believe that the article was published in a Christian newspaper $(M=5.30)$ than were Muslims $(M=5.02)$, $t(75)=1.99, p=.050)$. It should be noted that $89 \%$ of the Muslims and $79 \%$ of the Christians circled a ' 5 ' on this scale, and that the scores ranged from a minimum of 4 to a maximum of 8 . This indicates that the bulk of the sample were not making guesses as to the nature of the newspaper.

3. Given the complexities associated with reporting three-way designs through regression-particularly when one of the independent variables is a three-level categorical variable-we have chosen to report the results through ANOVA using a median split on identification. It should be noted, however, that the interpretation of the effects reported below remain the same regardless of whether the analyses are conducted through ANOVA or through regression.
4. Contingency chi-square analysis showed that there were equal numbers of high and low identifiers across levels of religion $\left(\chi^{2}(1)=0.10\right.$, $p=.75)$, and across levels of newspaper $\left(\chi^{2}(2)=1.29, p=.52\right)$.

\section{Acknowledgments}

This research was conducted as part of the first author's PhD research. We thank Thomas Morton and three anonymous reviewers for their helpful comments on a previous version of this manuscript.

\section{References}

Arpan, L. M., \& Raney, A. A. (2003). An experimental investigation of news source and the hostile media effect. Journalism and Mass Communication Quarterly, 80, 265-281.

Brewer, M. B. (1981). Ethnocentrism and its role in interpersonal trust. In M. B. Brewer \& B. E. Collins (Eds.), Scientific inquiry and the social sciences (pp. 345-360). San Francisco: Jossey-Bass.

D'Alessio, D. (2003). An experimental examination of readers' perceptions of media bias. Journalism and Mass Communication Quarterly, 80, 282-294.

Duck, J. M., Terry, D. J., \& Hogg, M. A. (1998). Perceptions of a media campaign: The role of social identity and the changing intergroup context. Personality and Social Psychology Bulletin, 24, 3-16.

Ellemers, N., Kortekaas, P., \& Ouwerkerk, J. W. (1999). Self-categorisation, commitment to the group and group self-esteem as related but distinct aspects of social identity. European Journal of Social Psychology, 29, 371-389.

Giner-Sorolla, R., \& Chaiken, S. (1994). The causes of hostile media judgments. Journal of Experimental Social Psychology, 30, 165-180.

Gunther, A. C. (1992). Biased press or biased public? Attitudes toward media coverage of social groups. Public Opinion Quarterly, 56, 147-167.

Gunther, A. C., Christen, C. T., Liebhart, J. L., \& Chia, C.-Y. S. (2001). Congenial public, contrary press, and biased estimates of the climate of opinion. Public Opinion Quarterly, 65, 295-320.

Heine, S. J., Lehman, D. R., Markus, H. R., \& Kitayama, S. (1999). Is there a universal desire for positive self-regard? Psychological Review, 106, 766-794.

Hofstede, G. (1997). Cultures and organizations: Software of the mind. New York: McGraw-Hill. 
Hofstede, G. (2001). Culture's consequences (2nd ed.). Beverly Hills, CA: Sage.

Hogg, M. A. (2003). Social identity. In M. R. Leary \& J. P. Tangney (Eds.), Handbook of self and identity (pp. 462-479). New York: Guilford.

Hornsey, M. J., \& Imani, A. (2004). Criticizing groups from the inside and the outside: An identity perspective on the intergroup sensitivity effect. Personality and Social Psychology Bulletin, 30, 365-383.

Hornsey, M. J., Trembath, M., \& Gunthorpe, S. (2004). 'You can criticize because you care': Identity attachment, constructiveness, and the intergroup sensitivity effect. European Journal of Social Psychology, 34, 499-518.

Insko, C. A., Schopler, J., Hoyle, R. H., Dardis, G. J., \& Graetz, K. A. (1990). Individual-group discontinuity as a function of fear and greed. Journal of Personality and Social Psychology, 58, 68-79.

Kim, H., \& Markus, H. R. (1999). Deviance or uniqueness, harmony or conformity? A cultural analysis. Journal of Personality and Social Psychology, 77, 785-800.

Matheson, K., \& Dursun, S. (2001). Social identity precursors to the hostile media phenomenon: Partisan perceptions of coverage of the Bosnian conflict. Group Processes E Intergroup Relations, 4, 116-125.

Perloff, R. M. (1989). Ego-involvement and the third person effect of televised news coverage. Communication Research, 16, 236-262.

Schmitt, K. M., Gunther, A. C., \& Liebhart, J. L. (2004). Why partisans see mass media as biased. Communication Research, 31, 623-641.

Tajfel, H., \& Turner, J. C. (1979). An integrative theory of intergroup conflict. In W. G. Austin \& S. Worchel (Eds.), The social psychology of intergroup relations (pp. 33-47). Monterey, CA: Brooks/Cole.

Triandis, H. C. (1972). The analysis of subjective culture. New York: Wiley.

Triandis, H. C. (1989). The self and social behaviour in differing cultural contexts. Psychological Review, 96, 506-520.

Triandis, H. C. (1995). Individualism and collectivism. Boulder, CO: Westview Press.

Triandis, H. C., Bontempo, R., Villareal, M. J., Asai, M., \& Lucca. N. (1988). Individualism and collectivism: Cross-cultural perspectives on selfingroup relationships. Journal of Personality and Social Psychology, 54, 323-338.

Turner, J. C. (1999). Some current issues in research on social identity and self-categorization theories. In N. Ellemers, R. Spears, \& B. Doosje (Eds.), Social identity: Context, commitment, content (pp. 6-34). Oxford, UK: Blackwell.

Vallone, R. P., Ross, L., \& Lepper, M. R. (1985). The hostile media phenomenon: Biased perception and perceptions of media bias in coverage of the Beirut massacre. Journal of Personality and Social Psychology, 49, 577-585.

Vivian, J. E., \& Berkowitz, N. H. (1992). Anticipated bias from an outgroup: An attributional analysis. European Journal of Social Psychology, 22, 415-424.

Worchel, S. (1979). Trust and distrust. In W. G. Austin \& S. Worchel (Eds.), The social psychology of intergroup relations (pp. 174-187). Monterey, CA: Brooks/Cole.

Yamagishi, T., \& Kiyonari, T. (2000). The group as the container of generalized reciprocity. Social Psychology Quarterly, 63, 116-132.

Paper received 22 November 2004; revised version accepted 18 August 2005.

\section{Biographical notes}

AMARINA ARIYANTO is a lecturer in the faculty of psychology, University of Indonesia. She recently completed her $\mathrm{PhD}$ at the University of Queensland, examining Muslim-Christian conflict in Ambon.

MATTHEW HORNSEY is a lecturer at the University of Queensland, Australia, and the Director of the Centre for Research on Group Processes. His research focuses on the social psychology of intergroup relations, identity threat, and the tension between individual and group will.

CYNTHIA GALLOIS is director of the Centre for Social Research in Communication at University of Queensland. Her research focuses on intergroup language and communication, especially in intercultural, health and organizational settings. 